\title{
PENGARUH PENGGUNAAN LARUTAN ALKALI DALAM UJI FOURIER TRANSFORM INFRARED PADA KOMPOSIT TERMOPLASTIK BERPENGISI SERBUK SERABUT KELAPA
}

\author{
Johannes Leonard S, Harry Abrido S, Maulida \\ Departemen Teknik Kimia, Fakultas Teknik, Universitas Sumatera Utara, \\ Jl. Almamater Kampus USU Medan 20155, Indonesia \\ Email : johannes.1.sitompul@ students.usu.ac.id
}

\begin{abstract}
Abstrak
Komposit merupakan gabungan dua bahan yang berlainan untuk memperoleh bahan dengan sifat-sifat fisik dan mekanik yang lebih baik dibandingkan sifat setiap komponen pembentuknya. Salah satu jenis komposit yang banyak dihasilkan adalah komposit berpengisi serbuk alami. Penelitian ini menggunakan matriks polipropilena bekas dan pengisi serbuk serabut kelapa yang telah diolah dengan Natrium Hidroksida (NaOH). Rasio perbandingan antara matriks dan pengisi adalah 85:15. Rasio ini merupakan nilai optimum yang diperoleh berdasarkan kekuatan uji tarik komposit dengan beberapa rasio yaitu 100:0 , 95:5, 90:10 dan 85:15. Tujuan penelitian ini adalah untuk mengetahui pengaruh penggunaan larutan alkali terhadap sifat komposit yang dihasilkan khususnya terhadap kadar lignin pada pengisi serbuk serabut kelapa dengan melihat karakteristik hasil uji Fourier Transform Infrared (FTIR) terhadap pengisi serabut kelapa dan komposit. Metode yang digunakan dalam pembuatan komposit ini adalah metode ekstrusi. Matriks berupa polipropilena bekas dicampur dengan serbuk serabut kelapa yang telah direndam dengan $\mathrm{NaOH}$, kemudian dicampur di dalam sebuah wadah, kemudian dimasukkan ke dalam ekstruder dengan suhu operasi $175^{\circ} \mathrm{C}$, dicetak dengan menggunakan hot press pada suhu $175^{\circ} \mathrm{C}$, dan dipotong-potong sesuai pengujian. Hasil penelitian menunjukkan bahwa terjadi pengolahan optimum dengan NaOH selama 2 hari. Hasil analisis FTIR terhadap sampel dapat dilihat bahwa telah terjadi perubahan gugus fungsi $-\mathrm{OH}$, dilihat dari bergesernya pita serapan $3417,04 \mathrm{~cm}^{-1}$ menjadi 3476,84 $\mathrm{cm}^{-1}$ pada serbuk serabut kelapa dan bergesernya pita serapan $3343,75 \mathrm{~cm}^{-1}$ menjadi 3192,33 $\mathrm{cm}^{-1}$ pada komposit, yang merupakan gugus $-O H$ dari lignin.
\end{abstract}

Kata kunci: komposit, polipropilena bekas, serabut kelapa, NaOH, uji FTIR, kadar lignin

\begin{abstract}
Composite is a combination of two different materials to obtain a material with physical and mechanical properties are better than any of its constituent parts. One of the composite types which is much produced is composite with powdered natural fiber filler. This research uses the used polypropylene matrix and powdered coconut fiber as filler treated with Sodium Hydroxide $(\mathrm{NaOH})$. The ratio of the matrix and the filler is 85:15. This ratio is the optimum value obtained by the composite tensile strength with ratio 100:0, 95:5, 90:10 and 85:15. The purpose of this study was to determine the effect of the use of an alkaline solution of the resulting composite properties especially towards lignin level, with Fourier Transform Infrared (FTIR) test on composite material used polypropylene with powdered coconut fiber as filler. The method used in the manufacture of composites is the method of extrusion. The matrix form of the used polypropylene mixed with coconut fiber powder that has been soaked with $\mathrm{NaOH}$, then mixed in a container, then put into the extruder operating temperature $175^{\circ} \mathrm{C}$, printed using a hot press at a temperature of $175^{\circ} \mathrm{C}$, and cut into pieces appropriate testing. The results showed that the optimum processing occurs with $\mathrm{NaOH}$ for 2 days. The FTIR test result, showed that $-\mathrm{OH}$ cluster switch occured, be seen from the shifting of absortion band from $3417.04 \mathrm{~cm}^{-1}$ to $3476.84 \mathrm{~cm}^{-1}$ for the powdered coconut fiber and the shifting of absortion band from $3343.75 \mathrm{~cm}^{-1}$ to $3192.33 \mathrm{~cm}^{-1}$ for the composite, which is the -OH cluster of the lignin.
\end{abstract}

Keywords : composite, used polypropylene, coconut fiber, NaOH, FTIR test, lignin level

\section{Pendahuluan}

Pada dekade terakhir ini perkembangan teknologi semakin pesat, terutama di bidang material. Salah satu kemajuan di bidang material adalah pemanfaatan bahan komposit untuk berbagai keperluan seperti alat transportasi baik transportasi darat, laut dan udara.
Komposit dengan berpenguat serat alam menjadi salah satu pilihan yang tepat. Serat alam lebih dipilih dibanding serat buatan karena serat alam memiliki beberapa kelebihan diantaranya adalah kaku, murah, ringan, tidak beracun, tersedia dalam jumlah yang banyak dan ramah lingkungan [4][7]. 
Adapun salah satu jenis tanaman yang menghasilkan serat alam adalah kelapa dengan nama latin Cocos nucifera. Selama ini serabut kelapa hanya digunakan sebagai bahan dasar pembuatan keset, sikat dan lain-lain [1]. Hal yang menjadi pertimbangan penggunaan serat ini adalah penggunaan serabut kelapa yang masih minim dan serat ini mudah diperoleh serta serat ini juga memiliki sifat yang kuat. Penelitian mengenai penggunaan serabut kelapa sebagai pengisi komposit termoplastik telah banyak dilakukan. Salah satu penelitian dilakukan oleh Prof. A. Beukers dkk. dimana komposit polipropilen (PP) berpengisi serabut kelapa menghasilkan flexural strength 29-49 MPa dan flexural stiffness 2,91-2,99 GPa [3].

Jenis termoplastik yang digunakan dalam penelitian ini adalah PP bekas dari cup plastik merk Aqua®. PP adalah sebuah polimer termoplastik yang dibuat oleh industri kimia dan digunakan dalam berbagai aplikasi.

Penggunaan larutan alkali sebagai langkah perlakuan terhadap serat telah dilakukan. Salah satunya dilakukan oleh Kuncoro dimana poliester berpengisi serat rami diperlakukan dengan larutan alkali yaitu larutan natrium hidrosida $(\mathrm{NaOH})$. Komposit yang dihasilkan memiliki tegangan tarik 190 MPa dan modulus elastisitas 45,795 GPa [4]. Penelitian yang dilakukan Rohatgi menyatakan perendaman serabut kelapa dalam larutan 5\% NaOH selama 72 jam memberikan kekuatan tarik terbaik [12]. Berbeda dengan Mohanty menyatakan perendaman dalam larutan $2 \% \mathrm{NaOH}$ selama 1 jam memberikan kekuatan tarik optimum [9].

Dikarenakan sifat dan karakteristiknya yang unik, kayu merupakan bahan yang paling banyak digunakan untuk keperluan konstruksi. Kebutuhan manusia akan kayu sebagai bahan bangunan baik untuk keperluan konstruksi, dekorasi, maupun furniture terus meningkat seiring dengan meningkatnya jumlah penduduk. Kebutuhan kayu untuk industri perkayuan di Indonesia diperkirakan sebesar 70 juta $\mathrm{m}^{3}$ per tahun dengan kenaikan rata-rata sebesar $14,2 \%$ per tahun sedangkan produksi kayu bulat diperkirakan hanya sebesar 25 juta $\mathrm{m}^{3}$ per tahun, dengan demikian terjadi defisit sebesar 45 juta $\mathrm{m}^{3}$ [11]. Kondisi ini menuntut penggunaan kayu secara efisien dan bijaksana, antara lain melalui konsep pemanfaatan seluruh bagian pohon, dan pengembangan produk-produk inovatif sebagai bahan bangunan pengganti kayu. Di lain pihak, seiring dengan perkembangan teknologi, kebutuhan akan plastik terus meningkat. Sebagai konsekuensinya, peningkatan limbah plastikpun tidak terelakkan. Limbah plastik merupakan bahan yang tidak dapat terdekomposisi oleh mikroorganisme pengurai (nonbiodegradable), sehingga penumpukkannya di alam dikhawatirkan akan menimbulkan masalah lingkungan. Oleh karena itu penelitian ini juga bermanfaat untuk mendaur ulang limbah plastik yaitu PP bekas dari kemasan plastik PP Aqua® untuk mengurangi penumpukan limbah plastik di alam.

\section{Teori}

Komposit adalah bahan padat yang dihasilkan melalui kombinasi dari dua atau lebih bahan yang berlainan dengan sifat-sifat yang lebih baik dan tidak dapat diperoleh dari setiap komponen penyusunnya. Komposit sudah digunakan oleh manusia sejak awal abad ke-12. Dewasa ini, pemakaian bahan komposit semakin banyak digunakan seperti dalam bidang penerbangan, konstruksi bangunan, otomotif, peralatan olahraga, perabot dan sebagainya [5].

Komposit mempunyai banyak kelebihan dan keistimewaan dari segi sifat mekanis, fisik, termal, dan kimianya, yaitu:

a) Sifat kekuatan, kekakuan dan keliatannya yang cukup baik .

b) Kestabilan dimensi dan ketahanan termal yang tinggi.

c) Peningkatan modulus spesifik (modulus/ massa jenis) dan kekuatan spesifik (kekuatan/ massa jenis) menyebabkan berat jenis komposit semakin berkurang.

d) Peningkatan ketahanan terhadap bahan kimia.

e) Biaya produksi dapat dikurangi karena bahan dasar yang digunakan berkurang

Namun perlu diketahui bahwa semua sifat di atas tidak dapat diperoleh secara bersamaan. Misalnya, peningkatan sifat kekakuan dan kekuatan umumnya mengurangi sifat keliatan bahan komposit tersebut. Jadi pencapaian kekuatan optimum komposit yang dihasilkan disesuaikan dengan penggunaan komposit tersebut[5].

Sodium Hydroxide atau Natrium Hidroksida adalah sejenis basa logam kaustik. Zat ini digunakan di berbagai macam bidang industri, kebanyakan digunakan sebagai basa dalam proses produksi bubur kayu dan kertas, tekstil, air minum, sabun dan deterjen. Kegunaan $\mathrm{NaOH}$ ini adalah untuk menghilangkan lignin, silika hemiselulosa, dan empulur dari serat agar memiliki impregnasi lebih baik antara serat dan matriks dan meningkatkan kekasaran permukaan serat agar dapat terjadi interaksi yang lebih baik 
yang menjadi tujuan utama pengolahan secara kimia [12].

PP merupakan polimer hidrokarbon yang termasuk ke dalam polimer termoplastik yang dapat diolah pada suhu tinggi. PP berasal dari monomer propilen yang diperoleh dari pemurnian minyak bumi. Struktur molekul propilen dapat dilihat pada gambar berikut.<smiles>C=CC</smiles>

\section{Gambar 1. Struktur Molekul Propilena}

Adapun karakteristik dari PP dapat dilihat pada Tabel 1 [13].

\section{Tabel 1. Karakteristik Polipropilen}

\begin{tabular}{|l|l|l|}
\hline Sifat-sifat & Nilai & Satuan \\
\hline Densitas & 0,9 & $\mathrm{~g} / \mathrm{cm}^{3}$ \\
\hline Tensile Strength & 360 & $\mathrm{~kg} / \mathrm{cm}^{2}$ \\
\hline Pemanjangan/Elongation & 8 & $\%$ \\
\hline $\begin{array}{l}\text { Laju alir pelelehan } \\
\left(230^{0} \mathrm{C} / 2,16 \mathrm{~kg}\right)\end{array}$ & 7,5 & $\begin{array}{l}\mathrm{g} / 10 \\
\text { menit }\end{array}$ \\
\hline $\begin{array}{l}\text { Daya serap air setelah } 24 \\
\text { jam }\end{array}$ & 0,02 & $\%$ \\
\hline $\begin{array}{l}\text { Modulus kelenturan } \\
\text { (Flexural modulus) }\end{array}$ & 17.000 & $\mathrm{~kg} / \mathrm{cm}^{2}$ \\
\hline Titik leleh & 176 & ${ }^{0} \mathrm{C}$ \\
\hline
\end{tabular}

Serabut kelapa berada diantara tempurung kelapa dan kulit kelapa. Setiap sel serat berbentuk panjang dan berongga dengan dinding tipis yang terbuat dari selulosa. Dinding ini lemah saat masih muda namun semakin lama semakin mengeras dan menguning dimana terbentuk lapisan lignin pada dindingnya. Tiap sel memiliki panjang $1 \mathrm{~mm}(0,04 \mathrm{in})$ dan berdiameter $10-20 \mu \mathrm{m}$ $(0,0004-0,0008$ in). Seratnya memiliki panjang $10-20 \mathrm{~cm}$ (4-12 in).

Tabel 2. Sifat-sifat Fisika Serabut Kelapa

\begin{tabular}{|l|l|l|}
\hline Sifat-sifat & Nilai & Satuan \\
\hline Densitas & 1,25 & $\mathrm{~g} / \mathrm{cm}^{3}$ \\
\hline Tensile Strength & 220 & $\mathrm{MPa}$ \\
\hline $\begin{array}{l}\text { Elongation } \\
\text { modulus }\end{array}$ & 6 & $\mathrm{GPa}$ \\
\hline $\begin{array}{l}\text { Elongation at } \\
\text { failure }\end{array}$ & $15-25$ & $\%$ \\
\hline
\end{tabular}

Terdapat 2 jenis dari serabut kelapa. Jenis pertama adalah berwarna coklat yang diperoleh dari kelapa yang sudah tua. Serat ini tipis, dan kuat sehingga digunakan untuk sikat dan keset kaki [2].

Adapun sifat-sifat fisika dan kimia dari serabut kelapa dapat dilihat pada Tabel 2 dan $3[3][8]$.

Tabel 3. Komposisi Kimia Serabut Kelapa

\begin{tabular}{|l|l|}
\hline Komposisi & Nilai (\%) \\
\hline Selulosa & $32-43$ \\
\hline Hemiselulosa & $0,15-0,25$ \\
\hline Lignin & $40-45$ \\
\hline Pektin & $3-4$ \\
\hline Kelembaban & 8 \\
\hline
\end{tabular}

\section{Hasil}

A. Karakteristik Hasil FTIR Pengisi Serbuk Serabut Kelapa Sebelum dan Setelah Perendaman $\mathrm{NaOH}$

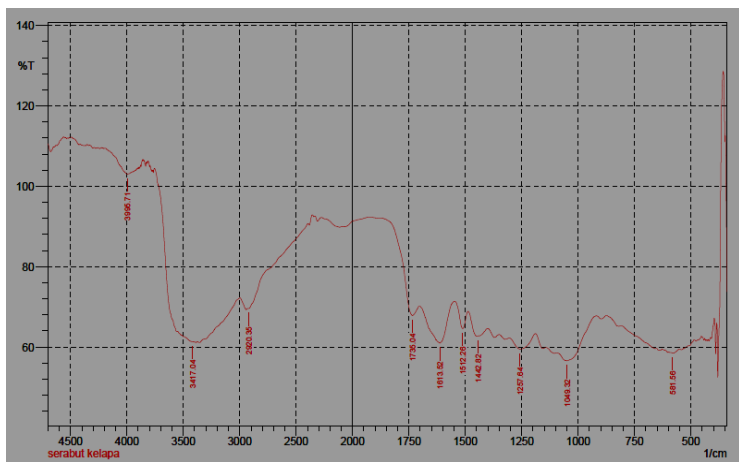

Gambar 2. Hasil FTIR Pengisi Serbuk Serabut Kelapa tanpa pengolahan $\mathrm{NaOH}$

Pada Gambar 2 terlihat bahwa serbuk serabut kelapa tanpa pengolahan $\mathrm{NaOH}$ memiliki gugus fungsi - $\mathrm{OH}$ yang tampak pada bilangan gelombang $3417,04 \mathrm{~cm}^{-1}$, regang C$\mathrm{H}$ pada bilangan gelombang $2920,35 \mathrm{~cm}^{-1}$. Adapun regang bilangan gelombang untuk gugus - $\mathrm{OH}$ adalah 3100-3600, sedangkan untuk regang bilangan $\mathrm{C}-\mathrm{H}$ adalah 2850-2970 $\mathrm{cm}^{-1}$ dan 2350-2480 $\mathrm{cm}^{-1}$ [10].

Setelah serbuk serabut kelapa mengalami pengolahan dengan $\mathrm{NaOH}$ maka kadar lignin dalam serat berkurang. Hal ini dapat dilihat dari hasil uji FTIR serbuk serabut kelapa pada Gambar 3.

Pada Gambar 3 terlihat bahwa serbuk serabut kelapa setelah pengolahan $\mathrm{NaOH}$ memiliki gugus-gugus fungsi $-\mathrm{OH}$ menjadi $3476,84 \mathrm{~cm}^{-1}$, dan $\mathrm{C}-\mathrm{H}$ pada bilangan gelombang $2390,87 \mathrm{~cm}^{-1}$ [10].

Dari Gambar 2 dan 3 terlihat terjadi pergeseran gugus fungsi setelah serbuk serabut kelapa diolah dengan $\mathrm{NaOH}$. Gugus $\mathrm{OH}$ pada bilangan gelombang $3417,04 \mathrm{~cm}^{-1}$ 
menjadi gugus $-\mathrm{OH}$ yang baru pada bilangan gelombang $3476,84 \mathrm{~cm}^{-1}$, dan gugus $\mathrm{C}-\mathrm{H}$ dari bilangan gelombang $2920,35 \mathrm{~cm}^{-1}$ menjadi gugus $\mathrm{C}-\mathrm{H}$ yang baru dengan bilangan gelombang $2390,87 \mathrm{~cm}^{-1}$.

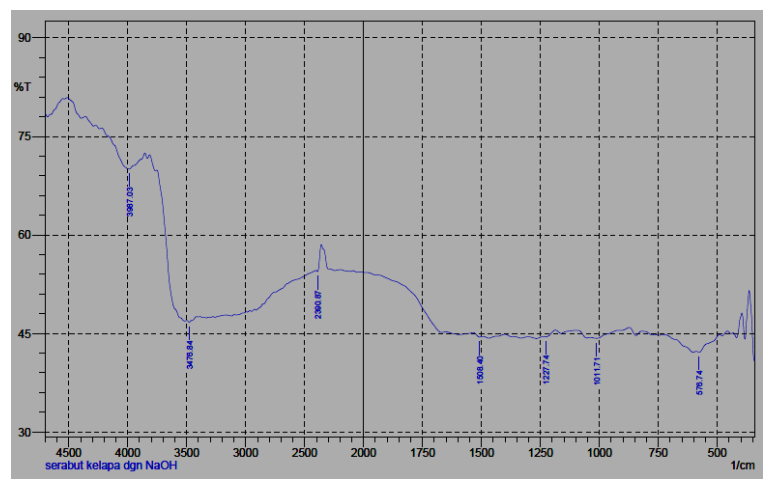

Gambar 3. Hasil FTIR Pengisi Serbuk Serabut Kelapa dengan pengolahan $\mathrm{NaOH}$

Pergeseran gugus - $\mathrm{OH}$ pada serbuk serabut kelapa disebabkan oleh berkurangnya kadar lignin yang memiliki gugus $-\mathrm{OH}$ di dalam serbuk serabut kelapa. Hal itu menyebabkan gugus $-\mathrm{OH}$ bergeser dari bilangan gelombang $3417,04 \mathrm{~cm}^{-1}$ ke 3476,84 $\mathrm{cm}^{-1}$. Adapun pengaruh larutan $\mathrm{NaOH}$ befungsi untuk menghilangkan lignin, hemiselulosa dan zat pengotor lainnya [6]. Kadar lignin yang bersifat nonpolar di dalam serbuk serabut kelapa berkurang yang menyebabkan tingkat kenon-polaran serbuk serabut kelapa berkurang sehingga adhesi antar muka matriks dengan pengisi pada komposit menjadi bagus [12].

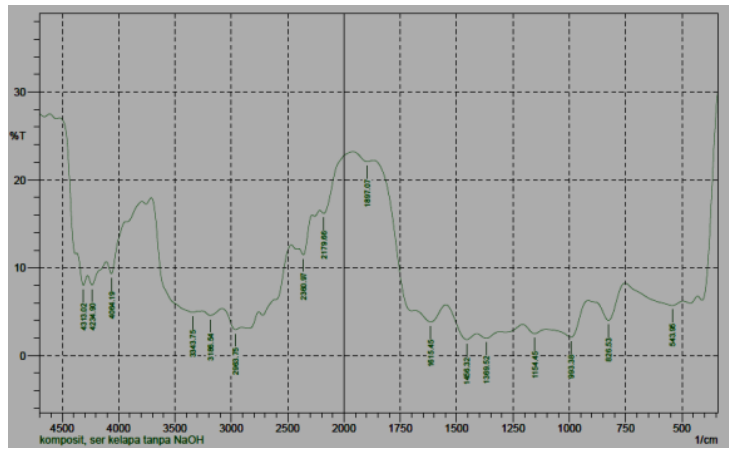

Gambar 4. Hasil FTIR Komposit tanpa pengolahan $\mathrm{NaOH}$

B. Karakteristik Hasil FTIR Komposit Polipropilena Bekas berpengisi Serbuk Serabut Kelapa tanpa dan dengan pengolahan $\mathrm{NaOH}$

Pada Gambar 4 terlihat bahwa komposit PP bekas berpengisi serbuk serabut kelapa tanpa pengolahan $\mathrm{NaOH}$ memiliki gugus fungsi - $\mathrm{OH}$ yang tampak pada bilangan gelombang $3343,75 \mathrm{~cm}^{-1}$. Adapun regang bilangan gelombang untuk gugus $-\mathrm{OH}$ adalah 3100-3600 [10]. Komposit PP bekas dengan pengisi serbuk serabut kelapa yang diolah dengan $\mathrm{NaOH}$ mengalami pengurangan kadar lignin di dalam serat. Hal ini dapat dilihat dari hasil uji FTIR komposit pada Gambar 5 di bawah.

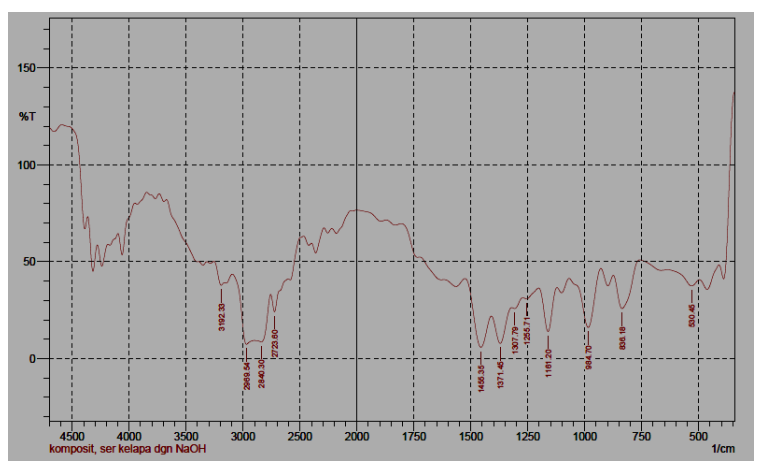

\section{Gambar 5. Hasil FTIR Komposit dengan pengolahan $\mathrm{NaOH}$}

Pada Gambar 5 terlihat bahwa komposit dengan pengisi diolah $\mathrm{NaOH}$ memiliki gugus fungsi-OH menjadi $3192,33 \mathrm{~cm}^{-1}$ [10].

Dari Gambar 4 dan 5 terlihat terjadi pergeseran gugus fungsi setelah pengisi komposit diolah dengan $\mathrm{NaOH}$. Gugus $-\mathrm{OH}$ pada bilangan gelombang 3343,75 $\mathrm{cm}^{-1}$ menjadi gugus $-\mathrm{OH}$ yang baru pada bilangan gelombang $3192,33 \mathrm{~cm}^{-1}$. Pergeseran gugus $\mathrm{OH}$ pada komposit disebabkan oleh berkurangnya kadar lignin di dalam pengisi yaitu serbuk serabut kelapa, dimana lignin tersebut memiliki gugus fungsi $-\mathrm{OH}$. Hal ini yang menyebabkan gugus $-\mathrm{OH}$ bergeser dari bilangan gelombang $3343,75 \mathrm{~cm}^{-1}$ ke 3192,33 $\mathrm{cm}^{-1}$. Adapun pengaruh larutan $\mathrm{NaOH}$ befungsi untuk menghilangkan lignin, hemiselulosa dan zat pengotor lainnya [6]. Kadar lignin yang bersifat nonpolar di dalam serbuk serabut kelapa berkurang yang menyebabkan tingkat kenon-polaran serbuk serabut kelapa berkurang sehingga adhesi antar muka matriks dengan pengisi pada komposit menjadi bagus [12].

\section{Kesimpulan}

Adapun kesimpulan yang didapat dari penelitian ini adalah sebagai berikut:

1. Dari hasil analisis Fourier Transform Infrared (FTIR) terhadap serbuk serbut kelapa dan komposit yang diolah dan tidak diolah dengan $\mathrm{NaOH}$, dapat dilihat bahwa 
telah terjadi perubahan gugus fungsi $-\mathrm{OH}$. Hal ini dapat dilihat bergesernya pita serapan $3417,04 \mathrm{~cm}^{-1}$ menjadi $3476,84 \mathrm{~cm}^{-1}$ dan $3343,75 \mathrm{~cm}^{-1}$ menjadi $3192,33 \mathrm{~cm}^{-1}$ yang merupakan gugus $-\mathrm{OH}$ dari lignin.

2. Pengaruh larutan alkali pada serbuk serabut kelapa adalah mengurangi kadar lignin yang bersifat non polar sehingga tingkat kenonpolaran serbuk serabut kelapa berkurang.

\section{Daftar Pustaka}

[1] Anonim, Coir, http//www. wikipedia. org, Diakses 4 April 2011, 2010a.

[2] Anonim, Polypropilene, http// www. wikipedia.org, Diakses 4 April 2011, 2010b.

[3] Beukers, Prof. A., dkk, Composite Applications using Coir Fibres in Sri Lanka, Netherlands: Delft University of Technology, 2004.

[4] Diharjo, Kuncoro, Pengaruh Perlakuan Alkali terhadap Sifat Tarik Bahan Komposit Serat Rami-Polyester, Universitas Negeri Sebelas Maret, 2006.

[5] Ismail, H, Komposit Polimer Diperkuat Pengisi dan Gentian Pendek Semula Jadi, Malaysia: Universiti Sains Malaysia, 2004.

[6] Jayabal, Effect of Soaking Time and Concentration of $\mathrm{NaOH}$ Solution on Mechanical Properties of Coir-Polyester Composites, Indian Academy of Sciences, 2011.

[7] Joseph K., dkk, Effect of Ageing on The Physical and Mechanical Properties of Short Sisal Fibre Reinforced Polyethylene Composites, Oxford: Composites Science Technology, 1995.

[8] Luqman, Faruq, Coconut Coir as Natural Fibers For Polymer Composites, Perlis: University Malaysia Perlis, 2008.

[9] Mohanty, A. K, Coir-Polyester Composites: Effect on Fibre Surface Treatment on Mechanical Properties of Composite, India, 2000.

[10] Niemann, Principle of Instumental Analysis, New York: USA, 1998.

[11] Priyono, SKS, Komitmen Berbagai Pihak dalam Menanggulangi Illegal Logging, Jakarta : Konggres Kehutanan Indonesia III, 2001.

[12] Rohatgi, P. K, Alkali Treatment for Coir Fibres for Coir-Polyester Composites, India, 1983.
[13] Titan PP Polymers, Catalog of Chemicals, Titan PP Polymers (M) Sdn. Bhd. Malaysia, 1999. 